\title{
EDITORIAL LOS TEMAS PARA UN CIERRE
}

Cómo citar: Ulloa Hung, J. (2021). Editorial. Los temas para un cierre. Ciencia y Sociedad, 46(4), 3-6. Doi: https://doi.org/10.22206/ cys.2021.v46i4.pp 3-6

A inicios del año que ahora culmina Ciencia y Sociedad asumió el reto de transformar su alcance, con el objetivo de continuar su crecimiento en cuanto a calidad con un enfoque orientado hacia la difusión científica. Esos ajustes han significado transformaciones estructurales y de calidad del flujo editorial, pero, sobre todo, han iniciado los cimientos para contribuir de manera más enfática en el camino hacia la trandicisplinariedad y multidisciplinariedad que actualmente demandan las Ciencias Sociales y las Humanidades en la República Dominicana y el Caribe. Aportar con creces a esa apertura y redimensionamiento de las disciplinas sociales y humanísticas, que a su vez implica mayor compromiso con su descolonización, es un meta esencial de Ciencia y Sociedad para el año 2022.

Ciencia y Sociedad se ha convertido en un espacio relevante de difusión científica para el área del Caribe, y transita hacia una mayor consolidación tanto en el ámbito de Latinoamérica como a nivel global, esto se evidencia en sus actuales niveles de internacionalización. Sin embargo, más que una meta cumplida es un nuevo peldaño en su empeño por proveer una lectura regional y caribeńa sobre temas y retos globales que contribuyan con el debate académico riguroso desde nuestro contexto geográfico. Fomentar el diálogo y el debate entre diferentes discursos teóricos y líneas de investigación en Ciencias Sociales y Humanidades, y entre estas y otras disciplinas, es y será el propósito más legítimo de la revista y su compromiso constante.

En el volumen 45, número 2 del año 2020, Ciencia y Sociedad inició sus páginas con una contribución que, desde una perspectiva diacrónica y crítica, reflexionaba sobre la evolución y el estado de la Ciencia y la Tecnología en la República Dominicana ${ }^{1}$. En la apertura de este número de cierre del año 2021 Ciencia y Sociedad retoma una de las aristas más complejas de este tema, la evaluación de los proyectos de investigación, desarrollo e innovación.

\footnotetext{
${ }^{1}$ Para consultar este artículo véase Riggio-Olivares, G. (2020). Evolución y estado actual de la ciencia y la tecnología en República Dominicana. Ciencia y Sociedad, 45(2), 7-32. https://doi.org/10.22206/cys.2020.v45i2.pp7-32.
} 
La reflexión teórica crítica sobre los criterios de evaluación utilizados por instituciones de educación superior y entidades de gestión científica en América Latina para este tipo de proyectos es el tema central de la colaboración que inicia este volumen 46 número 4 de la revista.

A partir de la selección y análisis de núcleos de información relevante y diversa, que expone criterios e indicadores de evaluación de proyectos de investigación en el último quinquenio, esta colaboración no solo reflexiona de manera crítica sobre los mismos, también reconsidera y propone nuevos criterios genéricos que pueden contribuir a la formulación de las evaluaciones. Criterios que emergen de una metodología que privilegia el análisis comparativo y la consideración de las diversas expectativas que promueven los programas e instituciones relacionadas con la creación de proyectos $\mathrm{I}+\mathrm{D}+\mathrm{i}$.

Uno de los aspectos más relevantes de este artículo es su capacidad para revelar que en América Latina la sostenibilidad financiera y económica ha sido el enfoque evaluativo predominante para este tipo de proyectos. De ahí que, proponer nuevos criterios con enfoque genérico a partir de los resultados de la investigación no solo contribuye a diversificar la composición de indicadores evaluativos, sino también alerta sobre la necesidad de adecuar las metodologías creativas de proyectos tanto al debate entre investigadores y académicos como hacia la participación de las comunidades potencialmente beneficiadas. En esencia, y como bien dicen los autores, evaluar las metodologías ex ante para medir su efectividad puede contribuir a mejoras sustanciales en los procesos de evalutivos de proyectos $\mathrm{I}+\mathrm{D}+\mathrm{i}$, además de disminuir sus posibilidades de fracaso.

Dentro de las colaboraciones que incluye este número de Ciencia y Sociedad, un núcleo importante está orientado hacia temas de salud mental. Estos temas son abordados en diferentes circunstancia, contextos y formas de afección. Por ejemplo, las estrategias implementadas para mantener el bienestar psicológico entre estudiantes universitarios dominicanos durante la pandemia de COVID-19 son exploradas a partir del uso de herramientas y modelos estadísticos. En ese caso, el uso de esas herramientas permitió la creación de modelos de predicción para cada dimensión de bienestar psicológico analizada, además posibilitó establecer estrategias de afrontamiento como variables independientes y significativas. Los resultados más relevantes de este estudio resaltan cómo determinadas estrategias de afrontamiento pueden predecir el bienestar psicológico en el contexto de la pandemia y contribuir a sobrellevar la crisis que afecta el bienestar integral de los estudiantes. Sin embargo, también reflejan una mayor frecuencia de estrategias de afrontamiento negativas que predicen un menor bienestar. Un factor a considerar dentro estos resultados son sus potenciales implicaciones clínicas para desarrollar planes de intervención que protejan la salud mental de la población estudiantil afectada por las secuelas sociales generadas por la pandemia de COVID-19.

Los procesos migratorios y sus consecuencias han sido objeto de atención en diferentes momentos y contextos de América Latina. Ese interés comprende aspectos de orden político, económico, cultural, demográfico, o social, con énfasis marcado en las repercusiones de los procesos migratorios en países receptores. Un fenómeno menos estudiado son las consecuencias de esos procesos en los sujetos migrantes, especialmente los efectos psicológicos de su movilidad y adaptación a los nuevos espacios y sus realidades. Este último aspecto es en el que centra su atención otra de las colaboraciones del núcleo de trabajos relacionados con la salud mental, cuyo sector poblacional estudiado es uno de los más vulnerables y resentidos por las migraciones.

El discurso de la niñez como sujeto de migración forzada se aborda desde una muestra de niños venezolanos en los cuales se explora su significado del proceso migratorio, haciéndose papable algunas de 
sus idea y representaciones. El estudio con alcance exploratorio y enfoque cualitativo muestra de forma tangible expresiones de desarraigo, dificultades de integración y rechazo, así como sus discursos sobre contexto social que rodea a estos infantes. Uno de los aspectos relevantes que se desprenden de esta incursión exploratoria es la necesidad de programas con perspectivas multiculturales e inclusivas que contemplen y reconozcan los derechos y necesidades de ese sector dentro de la población migrante.

La población infantil vuelve a constituir objeto de atención en el último de los trabajos de este bloque de colaboraciones enfocadas en el tema de salud mental. En este caso, el interés se centra en estudiar el perfil de las funciones ejecutivas en una muestra de niños diagnosticados con Trastorno Negativista Desafiante (TND) residentes en la poblacion colombiana de Cali. El estudio, de naturaleza descriptiva-observacional y diseño no experimental, combina pruebas y herramientas propias de la psicología, como las evaluaciones neuropsicológicas, con representaciones cuantitativas para visibilizar los resultados obtenidos a través de una medición estandarizada de variables que evidenciaron bajo desempeño en la mayoría de las pruebas evaluadas. Los resultados del estudio no solo corroboran los obtenidos por investigaciones similares sobre este tema, también contribuyen a mejorar el diagnóstico e intervención del Trastorno Negativista Desafiante (TND) al evidenciar el peso de los factores neurobiológicos en algunas conductas manifestadas por niños diagnósticados con este trastorno.

La búsqueda de argumentos que puedan enriquecer o refutar la existencia de peregrinaciones hacia los espacios o recintos rituales especiales durante el período precolonial del Caribe, constituye el núcleo del último artículo incluido en la sección artículos originales. La aproximación a ese fenómeno se realiza a partir de dos elementos centrales, en primer lugar, las críticas a los planteamientos del investigador
Christopher T. Espenshade, al analizar algunos de los recintos rituales precolombinos de la isla de Puerto Rico, en especial el sitio conocido como Jácana y, en segundo lugar, el re-análisis de datos arqueológicos y de arte rupestre a varios de estos recintos en Puerto Rico y otras islas del Caribe.

Un elemento interesante de este artículo es su capacidad de integrar varias líneas de evidencias en función de argumentar sus críticas. A esto se une su capacidad de abrir nuevas interrogantes y proponer potenciales líneas de investigación sobre aspectos demográficos, manejos rituales y simbólicos del paisaje y el arte rupestre, asociado a poblaciones indígenas de Puerto Rico y el Caribe. Además, resalta el reclamo de desarrollar estos estudios desde una perspectiva multiescala para fomentar una comprensión holística de esos aspectos en la historia precolonial.

La sección Comentarios, que cierra este número de Ciencia y Sociedad, se enfoca en analizar desde una perspectiva filosófica y contemporánea el fenómeno poético y literario dominicano conocido como movimiento postumista. El análisis se desarrolla a partir de un conjunto de ejes teóricos que son pautas esenciales para evaluar el postumismo como un giro o abandono en la forma tradicional de concebir la poesía al momento de surgir el movimiento. Ese giro, que implicó un enfoque hacia lo emocional como rasgo estético, es uno de los elementos más interesantes del análisis, especialmente porque su deconstrucción filosófica y estética revela las formas en que el postumismo transformó la poesía y la literatura a través de la exaltación de lo cotidiano y lo autóctono, aspecto que no está desligado del interés por la autonomía de pensamiento y la dignificación de la vida del dominicano.

En esencia, el estudio del postumismo y el hecho de develar abiertamente lo que este representó como movimiento creativo poético y literario, nos convoca, desde otro momento y contexto, a dar respuestas a nuestros desafíos como individuos y como sociedad 
a partir de recursos más originales y autóctonos. A través de ellos, al igual que los cultivadores del arte poético postumista, transitar por rutas diferentes a lo trillado como forma de entender y comprender nuestras potencialidades como cultura, como pueblo y como nación; en otras palabras, y usando como metáfora el recurso de los postumistas, nuestro "acento emocional".

\section{Dr. Jorge Ulloa Hung}

Profesor Investigador del Instituto Tecnológico de

Santo Domingo (INTEC)

Director de Ciencia y Sociedad

Correo-e: jorge.ulloa@intec.edu.do

Página web: https://www.intec.edu.do 